\title{
EL ENFERMO TRANSPARENTE Y LA REHUMANIZACIÓN DE LA MEDICINA
}

\section{The transparent sick and the rehumanization of medicine}

\author{
María GONZÁLEZ; Begoña CANTABRANA; Agustín HIDALGO \\ e-mail: hidalgo@uniovi.es \\ Farmacología, Departamento de Medicina, Universidad de Oviedo. Instituto Universitario de Oncología del Principado de Asturias, \\ Fundación Cajastur. Instituto de Investigación Sanitaria de Asturias (ISPA) (España).
}

Fecha de recepción: 22 de junio de 2019

Fecha de aceptación: 2 de septiembre de 2019

Fecha de publicación: 15 de marzo de 2020

«Un diagnóstico es una especie de maldición moderna»

(Ian McEwan. Solar, 2012. P.269)

El Licenciado vidriera es una buena aproximación al título de este escrito, más por las cualidades inherentes al vidrio que por las que Cervantes puso en la conformación de su personaje, un caso de hipocondría grave. El buen Tomás Rodaja se pasó la vida extremando precauciones para no romperse dada la fragilidad que su condición entrañaba. Hoy, el vidrio y su transparencia son un buen indicativo del estado al que la tecnología nos ha llevado en muchos aspectos de la vida cotidiana, incluido el quehacer médico, a costa de nuestra privacidad y nuestra vida interior. Los medios de comunicación se hacen eco de historias personales contadas por los propios protagonistas; la televisión, la radio e internet ofrecen detalles de la privacidad de las personas hasta hace poco reservadas a la intimidad y al entorno próximo; los ciudadanos, cada vez con más soltura socializan conductas de la esfera personal, y las cámaras de vídeo gravan nuestros movimientos en un panóptico benthamiano del que aparentemente es casi imposible escapar.

El desarrollo tecno científico que ha permitido esta transformación social también ha incidido de forma decisiva en la medicina, en aspectos que afectan a algunos componentes de la nosología médica tales como el nivel cada vez más elemental de descripción de las enfermedades, los procesos diagnósticos y terapéuticos, el seguimiento de la evolución de la enfermedad, y la relación médico paciente. Todo ello ha ocurrido en el seno de la denominada cultura postmoderna y ha conducido a construir una imagen de omnipotencia de la ciencia (cientifismo) y de la medicina (biomedicina) que han contribuido a generar unas expectativas difíciles de alcanzar.
Por una parte, desde la introducción del estetoscopio en la práctica médica, el desarrollo técnico de la panoplia de técnicas radiológicas, la cuantificación de parámetros bioquímicos, la detección de marcadores de patologías cada vez más abundantes y el advenimiento de los algoritmos diagnósticos basados en big data, permiten al médico tener información del funcionamiento del cuerpo humano sin necesidad de tocar al enfermo. Imbuido del poder científico el médico ha devenido, con frecuencia, en un profesional frío que parece que no ve al paciente como una persona, como si para ellos no tuvieran cara, ni nombre, ni familia, como si únicamente les importara la enfermedad. Por ello son percibidos como alejados, porque da la impresión de que quieren poner distancia entre los pacientes y ellos, olvidando que la empatía es la base de la medicina. Para los médicos, escribió Anatole Broyard «mi enfermedad no es más que un incidente en su labor profesional diaria, mientras que para mí constituye la tragedia de mi vida ${ }^{1}$. Ese déficit de ponerse en el sitio del paciente, de captar su realidad social y emocional más allá de la biológica, es un componente esencial de la que ha dado en llamarse deshumanización de la medicina o deshumanización de la atención sanitaria.

Pero además, la alta eficiencia de las pruebas diagnósticas, con alguna frecuencia aporta información que conducen a diagnósticos sobre hechos irrelevantes que, una vez identificados, añaden congoja e incertidumbre al paciente y plantean la necesidad de su tratamiento, la medicalización, en suma, de la vida de una persona. Aquí radica el sentido de la expresión que pone lan McEwan en boca del protagonista de su novela Solar ${ }^{2}$. Un diagnóstico te cambia la vida, te convierte en una persona diferente, te deriva a una realidad ajena. 


\section{EL ENFERMO TRANSPARENTE Y LA REHUMANIZACIÓN DE LA MEDICINA MARÍA GONZÁLEZ; BEGOÑA CANTABRANA; AGUSTÍN HIDALGO}

El médico debe ser consciente de que toda la medicina científica junta, con su panoplia de ensayos clínicos, es incapaz de responder a los interrogantes que suponen la realidad emocional y compleja, única e irrepetible que plantea cada persona enferma en cada momento concreto. «El enfermo no lleva su estómago o su columna vertebral a que los visiten; va con todo él, con sus miedos y sus esperanzas»" "El enfermo te viene a ver para que le soluciones un problema. No podemos reducir el acto médico a que yo soy el médico experto en esta enfermedad, tú la padeces y yo te curo, como si llevásemos el coche al taller»".

Sean bienvenidos, pues, los avances científicos que han permitido salvar vidas, pero también parece claro que estos descubrimientos han tenido como precio una menor eficacia en el alivio del sufrimiento de los pacientes por centrar el acto médico en la biomedicina y olvidarse de los aspectos emocionales y sociales.

Por otra parte, la divulgación de los conocimientos científicos y del éxito de las prácticas médicas ha contribuido a la creación de una biocultura en la que «los miembros de las actuales sociedades occidentales mostramos ambivalencia respecto a lo que esperamos del sistema sanitario; por una parte, exigimos que se nos apliquen íntegramente los últimos logros tecnológicos a través del método científico pero, al mismo tiempo, deseamos que los agentes de salud nos traten con humanidad, no como meros organismos desprovistos de emociones, esperanzas, miedos y recuerdos $\aleph^{5}$. Además, las expectativas generadas en los medios por los avances científicos y los éxitos médicos terminan, en alguna medida, generando frustración en algún grado. De hecho, la percepción de la salud empeora, lo que ha llevado a decir que en la época en la que el nivel de salud de la población es más alto, la gente se siente peor. Lógicamente esto tiene que ver con el hecho de que los éxitos de la ciencia y la medicina han permeado la sociedad y el ciudadano hace propia la demanda de salud plena e inmediata. Cuando no se cumplen estas expectativas, surge frustración, depresión, desesperanza y malhumor.

Urge, por tanto, la implementación de las humanidades médicas tanto en la formación de los estudiantes como en la organización de la asistencia sanitaria ${ }^{6-8}$, más centrada actualmente en los procesos que en las personas. Por eso es tan bienvenido el nuevo impulso que reclama un trato más humano a los enfermos y recuerda que las humanidades médicas ayudan a ser mejores personas y mejores médicos porque ayudan a conectar mejor con el mundo del paciente y a meterse en su entramado vivencial ${ }^{9}$, como lo son los planes de humanización de la asistencia que se están implementando en buena parte de los hospitales españoles ${ }^{10}$.

\section{Referencias}

1. Broyard A. Ebrio de enfermedad. Segovia: Ediciones la Uña Rota; 2013.

2. McEwan I. Solar. 2a ed. Barcelona: Anagrama; 2011.

3. Broggi MA. El clínico y la esperanza del enfermo. Med Clin 2010; 134(5): 218-21.

4. Vilardell M. Ser médico. El arte y el oficio de curar. Barcelona: Plataforma Editorial; 2011.

5. Bayés R. Aprender a investigar, aprenderá a cuidar. Una guía para estudiantes y profesionales de la salud. Barcelona: Plataforma Editorial; 2012.

6. Guardiola E, Baños JE. El papel de las humanidades médicas en la educación de los profesionales de la salud del siglo XXI. Rev Med Cine [Internet] 2017; 13(4): 155-7.

7. González Blasco P, Boso Vachi VH, Subtil de Paula P, Antonio LJ de, Godoy J. Promoviendo la educación médica centrada en el paciente para los estudiantes de medicina: una experiencia de dos décadas en Brasil. Educ Med. 2017; 18(4): 276-84.

8. Millán Nuñez-Cortés, J. Humanización de la medicina, medicina humanizada, medicina humanista: ¿de qué estamos hablando? Educ Med. 2018; 19 (3): 131-2.

9. Zarco J. El arte de ser médico. Sanar, cuidar, acompañar. Barcelona: Ediciones Península; 2013.

10. Mouzo J. Cuidar además de curar. El País, 22 de abril de 2019.

\begin{tabular}{|c|c|}
\hline & $\begin{array}{l}\text { María González García es Diplomada en Enfermería y Fisioterapia. Máster en Enfermería de Urgen- } \\
\text { cias y Cuidados Críticos. Desarrolla su labor asistencial como enfermera de cuidados intensivos. } \\
\text { Colaboradora en un proyecto de innovación docente en Grado de Enfermeria de la Universidad de } \\
\text { Oviedo. En la actualidad desarrolla su tesis doctoral sobre el estudio de la ciencia, enfermedad y } \\
\text { medicamentos en la prensa diaria. }\end{array}$ \\
\hline & $\begin{array}{l}\text { Agustín Hidalgo Balsera es Licenciado y Doctor en Medicina por la Universidad Complutense de Madrid } \\
\text { y Profesor de Farmacología de la Universidad de Oviedo. Entre sus áreas de interés se encuentra la } \\
\text { repercusión social de los medicamentos y la representación social de la medicina y la enfermedad a } \\
\text { través de las manifestaciones artísticas y los medios de divulgación científica y comunicación social. }\end{array}$ \\
\hline & $\begin{array}{l}\text { Begoña Cantabrana Plaza es Licenciada y Doctora en Medicina por la Universidad de Oviedo y } \\
\text { Profesora Titular de Farmacología en la misma universidad. Su actividad científica se centra en la } \\
\text { farmacología hormonal y dedica atención preferente a diferentes aspectos de la innovación docente } \\
\text { en los Grados de Medicina y Enfermería. }\end{array}$ \\
\hline
\end{tabular}

